\title{
Wind-Driven Overturning, Mixing and Upwelling in Shallow Water: A Nonhydrostatic Modeling Study
}

\author{
Jochen Kämpf \\ College of Science and Engineering, Flinders University, GPO Box 2100, Adelaide, SA 5001, Australia; \\ jochen.kaempf@flinders.edu.au; Tel.: +61-8-8201-2214
}

Received: 30 May 2017; Accepted: 26 September 2017; Published: 2 October 2017

\begin{abstract}
Using a nonhydrostatic numerical model, this work demonstrates that onshore winds are a principal agent of overturning and vigorous vertical mixing in nearshore water of lakes and inner continental shelves. On short (superinertial) timescales of a few hours, onshore winds create surface currents pushing water against the shore which, via the associated pressure gradient force, creates an undercurrent. The resulting overturning circulation rapidly becomes dynamically unstable due to the Kelvin-Helmholtz instability mechanism, internal gravity waves form, and vigorous vertical mixing follows. The vertical extent of the overturning cell depends on the speed of surface currents and density stratification (which is influenced by other processes such as tidal mixing). In smaller enclosed water bodies, wave reflection in conjunction with dynamical instabilities support rapid mixed-layer deepening and overturning of the entire water column. Based on these findings, the author postulates that dynamic instabilities following from onshore wind events are of fundamental importance to biogeochemical cycles and ecological processes in shelf seas and lakes.
\end{abstract}

Keywords: oceanography; limnology; vertical mixing; overturning; upwelling; shallow water; nonhydrostatic modelling

\section{Introduction}

The physical processes of upwelling (i.e., upward currents) and vertical mixing are vital for aquatic food webs as they operate to lift or entrain sub-surface water of higher dissolved nutrient levels back into the euphotic zone-fuelling primary production. The physics of wind-driven upwelling processes in the coastal ocean are relatively well understood for situations in which the classical Ekman layer theory applies [1,2]. In this situation, alongshore wind creates offshore flow in the surface Ekman layer. This lowers the coastal sea level inducing a coast-parallel geostrophic upwelling jet that induces onshore flow in the bottom Ekman layer. Finally this onshore flow is converted to vertical flow (upwelling) closer to the shore due to a convergence of Ekman transports. Classical Ekman theory also explains upwelling events in larger lakes such as Lake Ontario or Lake Michigan [3,4].

Two conditions must be met for the Ekman theory to apply. First, the timescale, $t$, of the wind forcing has to be long enough for the Coriolis force and Ekman layers to fully establish. This can be expressed as $t>t_{f}$ where $t_{f}=2 \pi /|f|$ ( $f$ is the Coriolis parameter) is the inertial period. At midlatitudes, for example, this condition is met on timescales exceeding 1-2 days. Second, the water body-be it a continental shelf or a lake-has to be deep enough for a spatial separation of surface and bottom Ekman layers [5]. Based on this condition, we can define "shallow water" as the regime where surface and bottom Ekman layers overlap and interfere (Figure 1). In the ocean seas, this shallow-water regime is referred to as inner continental shelf [6]. Under the assumption that the thicknesses of surface and bottom Ekman layers, $d_{E}$, are similar, full interference can be expressed by the condition [5]:

$$
\delta=d_{E} / D<1
$$


with $D$ being total water depth. In this situation, Ekman-layer effects are virtually absent and wind-induced currents are aligned with the wind direction [5]. The thickness of the Ekman layer is influenced by $f$ (i.e., geographical location), wind stress magnitude and density stratification. As $d_{E}$ undergoes temporal variations, so does the offshore extent of the shallow-water zone. In general, the shallow-water regime, as defined by Equation (1), may extend offshore in coastal oceans to total water depths of $10-50 \mathrm{~m}$. This is beyond the surf zone (which typically extends offshore to $D \approx 5 \mathrm{~m}$ ) where breaking waves are the vehicle of intense mixing.

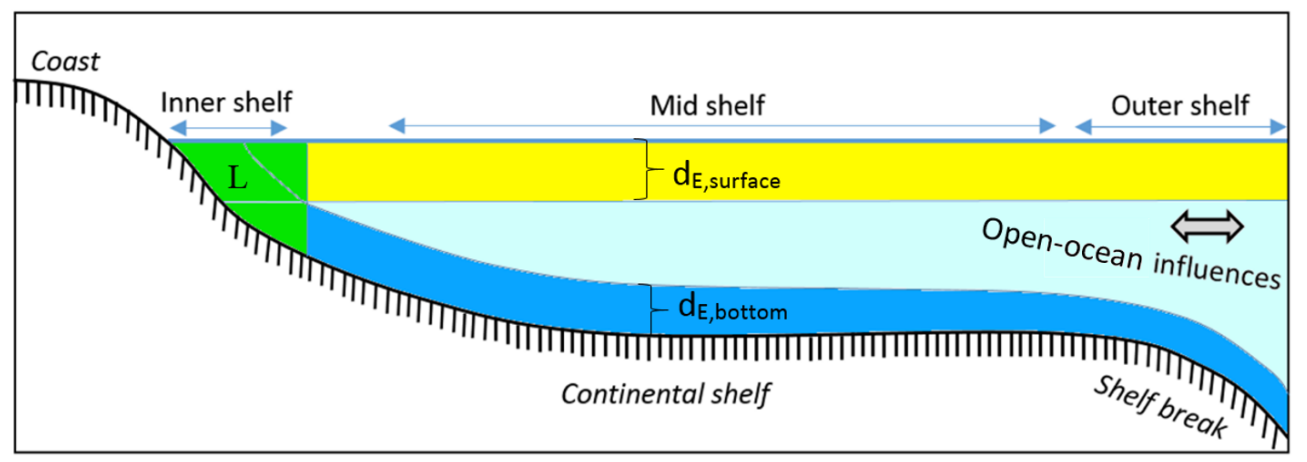

Figure 1. Schematic representation of different dynamic regimes on modern continental shelves. Influences by the adjacent open ocean are limited to the shelf-break region. The classical Ekman theory explaining wind-driven coastal upwelling is valid for the mid-shelf region where surface and bottom Ekman layers (marked by yellow and blue bands) are vertically separated. These frictional boundary layers interfere and partially or fully cancel out each other in shallow water, marked in green.

On longer timescales, $t>t_{f}$, alongshore flows on the mid-continental shelf are geostrophically balanced and Ekman layers (assisted by surface wave drift) induce an onshore/offshore overturning circulation. Both upwelling- and downwelling-favourable winds, if persisting long enough, can create a region of no or only little density stratification near the shore [6].

Conversely, in very shallow water $(\delta<1)$ on any timescale or in deeper water on super-inertial timescales $\left(t<t_{\mathrm{f}}\right)$ it is the offshore wind component that can create swift onshore/offshore flows. Surprisingly little is known about the dynamics associated with this regime [6], which is remarkable per se given that the shallow-water region is central to the transport of larvae, nutrients, low-oxygen water masses, sediment and pollutants between the shore and offshore water [6] (and references therein).

On continental shelves the classical Ekman upwelling circulation does not reach into shallow waters of the inner continental shelf. Instead, upwelling close to shores generally follows from offshore wind. This offshore wind moves water away from the shore and triggers a situation in which the water surface tends to slope against the wind direction. The associated onshore pressure gradient creates a shoreward undercurrent, and upwelling at the upwind shoreline follows from this (Figure 2b). This overturning circulation, historically referred to as "Leewirkung" (lee effect) [7], is a frequently observed feature in lakes [8-11], coastal oceans [12] and large positive estuaries such as the Baltic Sea [13]. Recent studies indicate that the lee effect triggers upwelling and significant phytoplankton blooms in the shallow Arafura Sea $[14,15]$.

Conversely, onshore winds should create an overturning circulation characterised by downwelling near the shore (Figure 2a), but little is known about this particular situation (see [6]), which is the focus of this work.

While exploring the lee effect with a nonhydrostatic model, the author made the surprising observation that situations of onshore rather than offshore winds trigger a dramatic dynamical response in the water column in the form of large-amplitude internal waves and strong vertical mixing. The aim of this work is to explore this situation of onshore wind events on superinertial timescales in more detail using the method of process-oriented numerical modelling [16,17]. 

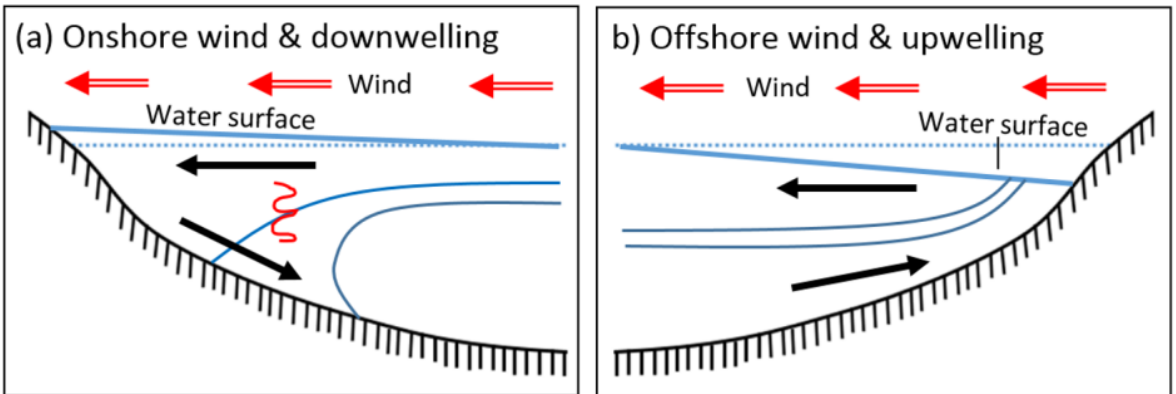

Figure 2. Schematic of the overturning circulation in shallow water, defined by (1), for (a) onshore wind leading to downwelling; and (b) offshore wind leading to upwelling, known as the lee effect.

The principal conclusion of this work is that onshore winds are an important agent of internal wave generation and vertical stirring in near-shore waters of lakes and continental shelves. For clarity it should be noted that the overall structure of the overturning circulation driven by onshore wind has been simulated with a hydrostatic numerical model before [18], but not the nonhydrostatic instability and mixing processes that follow from this. It should also be noted that there is ample previous work on the creation and modification of internal waves over variable bathymetry (e.g., [19-23]). None of these studies, however, explicitly addressed the situation discussed in the present work.

\section{Materials and Methods}

The model domain used in this work consists of a channel, 1-km wide and 20-m deep in central parts and bounded by shorelines on either side (Figure 3). To make the bathymetry more realistic as opposed to a channel with vertical sidewalls, total water depth is assumed to gradually deepen away from the shorelines to its maximum value over a distance of $200 \mathrm{~m}$. It should be pointed out that, irrespective of the shape of bathymetry chosen, the wind forcing will always create an undercurrent potentially leading to instability, vertical stirring and the generation of internal waves. Slope effects, as discussed by [22-24], are of secondary importance to the findings reported here.

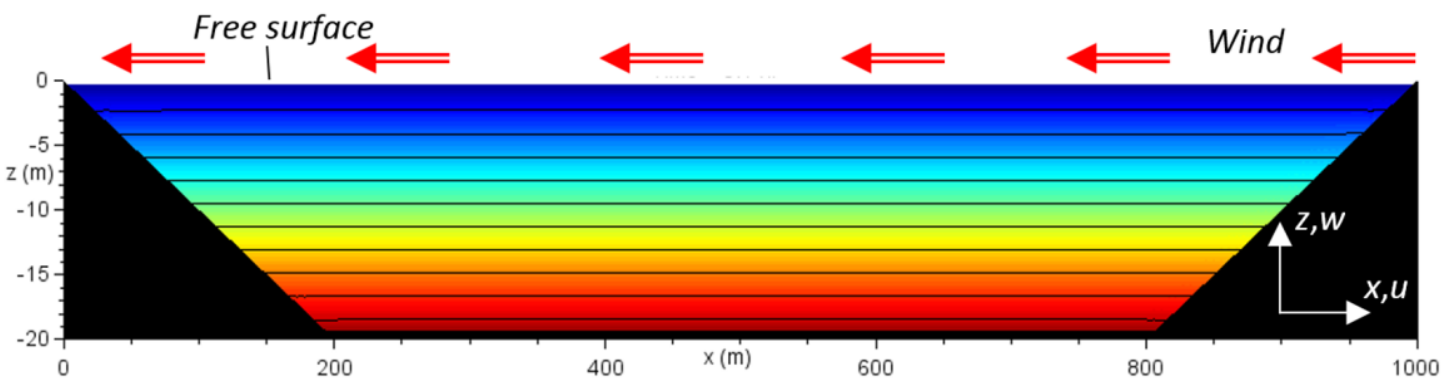

Figure 3. Model domain used in this study. Color shading denotes the initial concentration of an Eulerian concentration field. The prescribed wind stress is spatially uniform. See text for more details.

This study uses a high-resolution nonhydrostatic hydrodynamic model with a free surface, described in [17]. The model equations are cast in Cartesian coordinates. In contrast to sigma coordinates, this leads to a step-wise representation of sloping terrain, but associated effects on the simulated dynamics are negligible. The dynamic pressure field including anomalies due to fluctuations of the fluid's free surface is iteratively derived from a Successive Over-Relaxation (SOR) scheme. To minimize numerical diffusion, advection is computed using a total variance diminishing (TVD) scheme with a Superbee limiter. See $[16,17]$ for more details and test cases. The model is applied in a numerical grid with isotropic grid spacing of $\Delta x=\Delta z=0.5 \mathrm{~m}$. This setting resolves turbulence elements of $>2.5-5 \mathrm{~m}$ in size (see [17]), which is sufficient for the purpose of this study. The focus 
of this study are timescales $<10 \mathrm{~h}$ characteristic of the passage of atmospheric fronts or the onset time of sea breezes, for examples. The numerical time step is set to $\Delta t=0.5 \mathrm{~s}$, constrained by the Courant-Friedrichs-Levy (CFL) or CFL stability condition associated with the propagation speed of barotropic surface gravity waves [17].

The rotational timescale inherent with frictional Ekman layers of relevance to cross-shelf exchanges at midlatitudes is of the order of 1-2 days [1], which is beyond the timescale considered in this work. On the other hand, short-lived wind bursts can give rise to inertial oscillations that can induce strong onshore or offshore flows within timescales of a few hours. For simplicity, such rotational effects are not considered in this work; that is, the Coriolis force is not included in the model equations. Using the Boussinesq approximation, the momentum conservation equations can then be written as:

$$
\begin{gathered}
\frac{\partial u}{\partial t}+u \frac{\partial u}{\partial x}+w \frac{\partial u}{\partial z}=-\frac{1}{\rho_{o}} \frac{\partial P}{\partial x}+\frac{\partial}{\partial x}\left(A_{x} \frac{\partial u}{\partial x}\right)+\frac{\partial}{\partial z}\left(A_{z} \frac{\partial u}{\partial z}\right) \\
\frac{\partial w}{\partial t}+u \frac{\partial w}{\partial x}+w \frac{\partial w}{\partial z}=-\frac{1}{\rho_{o}} \frac{\partial P}{\partial z}-\frac{\rho^{\prime}}{\rho_{o}} g+\frac{\partial}{\partial x}\left(A_{x} \frac{\partial w}{\partial x}\right)+\frac{\partial}{\partial z}\left(A_{z} \frac{\partial w}{\partial z}\right)
\end{gathered}
$$

where $t$ is time, $x$ and $z$ are Cartesian coordinates ( $z$ pointing upwards), $u$ and $w$ are velocity components, $\rho_{o}$ is mean density set to $1026 \mathrm{~kg} / \mathrm{m}^{3}, P$ is dynamic pressure, $\rho^{\prime}$ is density anomaly, $g=9.81 \mathrm{~m} / \mathrm{s}^{2}$ is acceleration due to gravity, and $A_{x}$ and $A_{z}$ are horizontal and vertical eddy viscosities. Under the assumption that $A_{x}=A_{z}$, the latter are diagnosed from Kochergin's turbulence closure [25], that can be expressed as:

$$
A_{z}=c^{2}(\Delta x \Delta z)^{2} \sqrt{\left(\frac{\partial u}{\partial z}\right)^{2}+\left(\frac{\partial w}{\partial x}\right)^{2}-N^{2}}
$$

where $N^{2}=-\mathrm{g} / \rho_{0} \partial \rho / \partial_{z}$ is the stability frequency squared, and the free parameter $c$ is set to 0.1 . The lower bound of viscosity is set to a molecular value of $10^{-6} \mathrm{~m}^{2} / \mathrm{s}$. The upper bound is set to $0.05 \mathrm{~m}^{2} / \mathrm{s}$. A minimum value of $0.001 \mathrm{~m}^{2} / \mathrm{s}$ is applied near the surface representing background wind stirring. It should be highlighted that the model resolves super-grid-scale turbulence developing at low Reynolds numbers such as density-driven convection or shear-flow instabilities; that is, there is no need for additional parameterizations of those processes.

At the surface, wind forcing is implemented via the boundary condition:

$$
A_{z} \frac{\partial u}{\partial z}=\frac{\tau_{x}}{\rho_{o}}
$$

where $\tau_{x}$ is the wind stress component along the $x$ axis. A quadratic friction law with a friction parameter of $r=0.001$ is used for $u$ in the bottom-nearest grid cells. Changing the value of $r$ within a reasonable range had no significant impact on the predictions. Under the assumption of a linear equation of state, the evolution of density anomalies can be predicted from the advection-diffusion equation:

$$
\frac{\partial \rho^{\prime}}{\partial t}+u \frac{\partial \rho^{\prime}}{\partial x}+w \frac{\partial \rho^{\prime}}{\partial z}=\frac{\partial}{\partial x}\left(k_{x} \frac{\partial \rho^{\prime}}{\partial x}\right)+\frac{\partial}{\partial z}\left(k_{z} \frac{\partial \rho^{\prime}}{\partial z}\right)
$$

where eddy diffusivities $\left(k_{x}=k_{z}=A_{x}=A_{z}\right.$ ) are based on a turbulent Prandtl number of unity.

Volume conservation comes in two forms in the model. One form is the so-called continuity equation, valid for any volume element within the model domain, which can be expressed as:

$$
\frac{\partial u}{\partial x}+\frac{\partial w}{\partial z}=0
$$

On the other hand, vertical integration of Equation (7) gives a prognostic equation for surface pressure, $P_{S}$, which is associated with the fluid's surface elevation. This equation can be written as: 


$$
\frac{\partial P_{s}}{\partial t}=\rho_{o} g \frac{\partial(\langle u\rangle D)}{\partial x}
$$

where the vertical integral of $u$ can be expressed as product of the vertically averaged value, $\langle u\rangle$, and total water depth, $D$. Note that Equation (8) continuously updates boundary pressure values used in Equations (2) and (3). Surface elevation can be derived from the hydrostatic relation $\eta=P_{s} /\left(\rho_{o} g\right)$.

In order to reveal turbulent mixing in situations of uniform density, a passive tracer field of concentration $C$ is used, that (analog to density anomalies) follows the advection-diffusion equation:

$$
\frac{\partial C}{\partial t}+u \frac{\partial C}{\partial x}+w \frac{\partial C}{\partial z}=\frac{\partial}{\partial x}\left(k_{x} \frac{\partial C}{\partial x}\right)+\frac{\partial}{\partial z}\left(k_{z} \frac{\partial C}{\partial z}\right)
$$

In contrast to density anomalies, which vanish for homogenous fluids, $C$ is initialized in a linear fashion in all model runs with a value of zero at the surface and value of unity in the deepest part of the model domain. This approach allows for a direct comparison of model simulations conducted with different density configurations. The numerical solver of Equations (2)-(9) is detailed in [17].

Three different stratification scenarios are considered in this work (Table 1). Density is uniform in the first scenario (A). In the second scenario (B), density initially varies linearly with depth according to a certain buoyancy frequency (squared) of $N^{2}=-g / \rho_{o} d \rho^{\prime} / d z$. This is varied between $1 \times 10^{-4} \mathrm{~s}^{-2}$ and $5 \times 10^{-4} \mathrm{~s}^{-2}$ in a sequence of model runs. The largest $N^{2}$ value used relates to a density change of $\sim 1 \mathrm{~kg} / \mathrm{m}^{3}$ over a depth of $20 \mathrm{~m}$. In lakes, this density change is equivalent to a top-to-bottom temperature difference of $\sim 6^{\circ} \mathrm{C}$. The third scenario (C) consists of a shallow surface mixed layer, 2 -m thick, that a pronounced pycnocline separates from weakly stratified $\left(N^{2}=1 \times 10^{-5} \mathrm{~s}^{-2}\right)$ deeper water. The density step, $\Delta \rho$, across the pycnocline is varied in a sequence of model runs from weak $\left(\Delta \rho=0.01 \mathrm{~kg} / \mathrm{m}^{3}\right)$ to relatively strong $\left(\Delta \rho=0.5 \mathrm{~kg} / \mathrm{m}^{3}\right)$. The total simulation time of experiments is $12 \mathrm{~h}$, using a numerical time step of $\Delta t=1 \mathrm{~s}$.

Table 1. Configuration of experiments discussed in the text.

\begin{tabular}{ccc}
\hline Scenario & Wind Stress $\tau_{x}$ & Stratification \\
\hline A & $-0.1 \mathrm{~Pa}$ & uniform density \\
$\mathrm{B}$ & -0.05 to $-0.15 \mathrm{~Pa}$ & linear $\left(N^{2}=1\right.$ to $\left.5 \times 10^{-4} \mathrm{~s}^{-2}\right)$ \\
$\mathrm{C}$ & $-0.1 \mathrm{~Pa}$ & layered ${ }^{1}\left(\Delta \rho=0.01\right.$ to $\left.0.5 \mathrm{~kg} / \mathrm{m}^{3}\right)$ \\
\hline
\end{tabular}

In each model run, the wind stress is linearly increased from zero to its final (spatially uniform) value over the first simulation hour. This adjustment is required to avoid the creation of an initial burst of unwanted gravity waves [17]. The wind-stress magnitude is varied from 0.05 to $0.15 \mathrm{~Pa}$ in a series of experiments, corresponding to $10-\mathrm{m}$ wind speeds in a range of $5-10 \mathrm{~m} / \mathrm{s}$.

At the request of one of the three referees, the author repeated selected experiments with a 2.5-dimensional version of the model (see [17]) that includes the Coriolis force with a Coriolis parameter of $f=1 \times 10^{-4} \mathrm{~s}^{-1}$ (mid-latitudes of northern hemisphere). This model allows for the creation of alongshore flows perpendicular to the two-dimensional model domain. Consistent with basic scaling considerations, these studies confirm that rotational effects are insignificant on super-inertial timescales of a few hours considered here (see results section).

\section{Results}

This section presents the simulation results for the three different density stratification scenarios outlined above. 


\subsection{Scenario A: Uniform Density}

The wind forcing imposed $\left(\tau_{x}=-0.1 \mathrm{~Pa}\right.$ ) leads to the establishment of upwelling near the upwind shore of the model domain (Figure 4). This is the lee effect, as described in [4,7]. The source of the upwelling is an undercurrent that operates to move sub-surface onshore and then upward on the sloping floor towards the surface. Here, in the absence of density stratification, the upwelling extends to the bottom water.
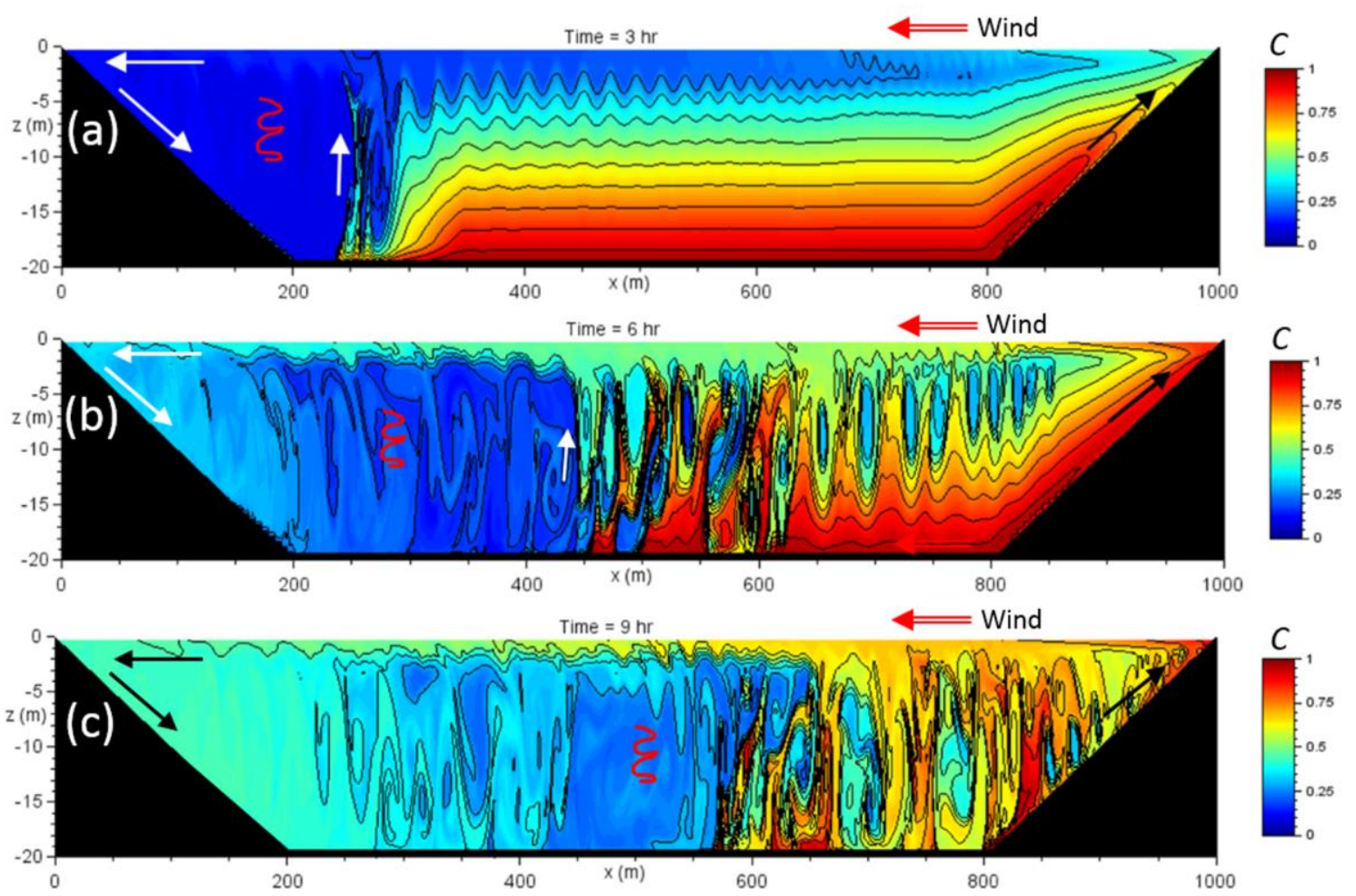

Figure 4. Scenario A $(N=0)$ with $\tau_{x}=-0.1 \mathrm{~Pa}$. Shown is the evolution of the concentration field $C$ after (a) $3 \mathrm{~h}$, (b) $6 \mathrm{~h}$ and (c) $9 \mathrm{~h}$ of simulation. Arrows indicate flows. Wiggly curves indicate vertical stirring. See GIF Animation S1 for a simulation of this experiment.

While this lee effect is happening on the upwind shore, a much more dramatic dynamic behaviour develops near the downwind shore (see Figure 4a). Here, the wind pushes surface water, marked by low values of $C$, against the shore and downward returning as an undercurrent in the opposite direction. Dynamic instabilities develop as a consequence of this overturning circulation and induce vigorous vertical stirring throughout most of the water column. After $12 \mathrm{~h}$ of simulation, the mixed region has extended upwind from the shore over a distance of $\sim 700 \mathrm{~m}$ (Figure $4 \mathrm{c}$ ), which corresponds to a lateral displacement speed of $\sim 3-4 \mathrm{~cm} / \mathrm{s}$.

The overturning circulation consists of a downwind surface flow (up to $40 \mathrm{~cm} / \mathrm{s}$ in speed) in the uppermost 2-3 $\mathrm{m}$ of the water column and an undercurrent below ( 10-20 cm/s) (Figures 5a and 6b). Note that another weak downwind current of a few $\mathrm{cm} / \mathrm{s}$ in speed establishes close to the bottom. The undercurrent pattern displays strong horizontal variations (Figure 5b). These variations occurs in conjunction with the appearance of vertical turbulent vortices, seen in alternating zones of positive and negative vertical velocities of up to $6 \mathrm{~cm} / \mathrm{s}$ in speed (Figure $6 \mathrm{c}$ ). At some locations, vortices operate to reduce the velocity of the undercurrent higher up in the water column, while enhancing it farther down. In other regions, vortices of the opposite sense of rotation operate the other way around. The vortices developing here have an aspect ratio (ratio of horizontal to vertical scale) of $\sim 1$, which is a typical for nonhydrostatic stirring processes [17]. Vertical velocities tend to peak in the middle of the water column (Figure 6c). 

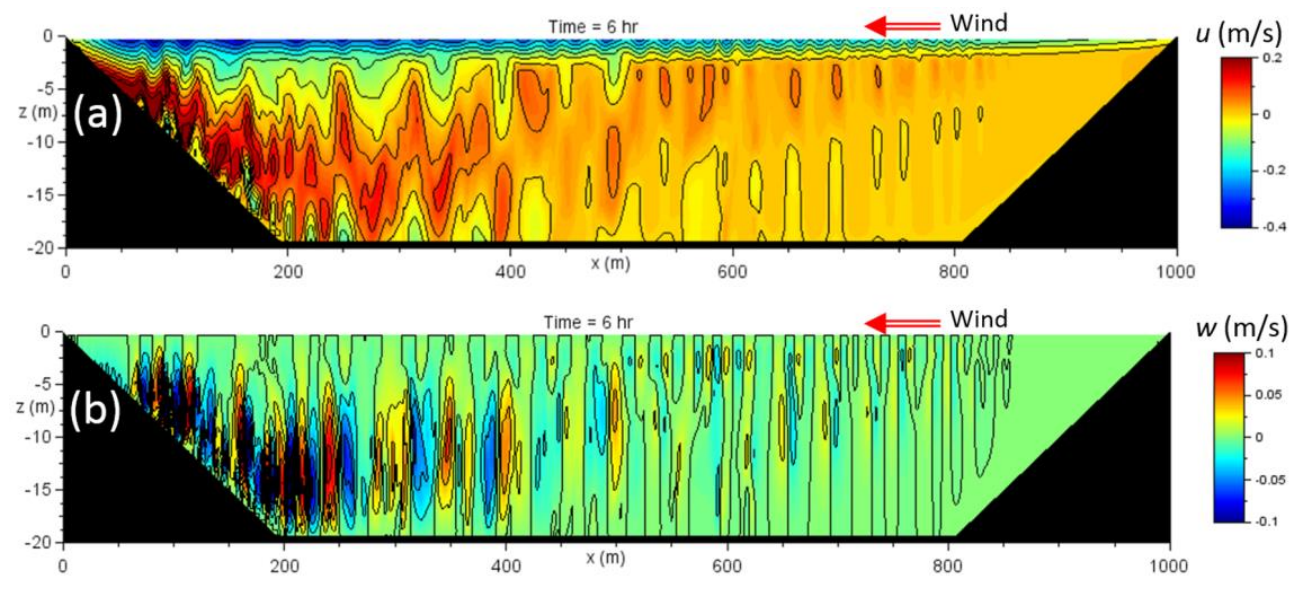

Figure 5. Scenario A $(N=0)$ with $\tau_{x}=-0.1 \mathrm{~Pa}$. Shown are the distributions of (a) horizontal velocity $u$ and (b) vertical velocity $w$ after $6 \mathrm{~h}$ of simulation.
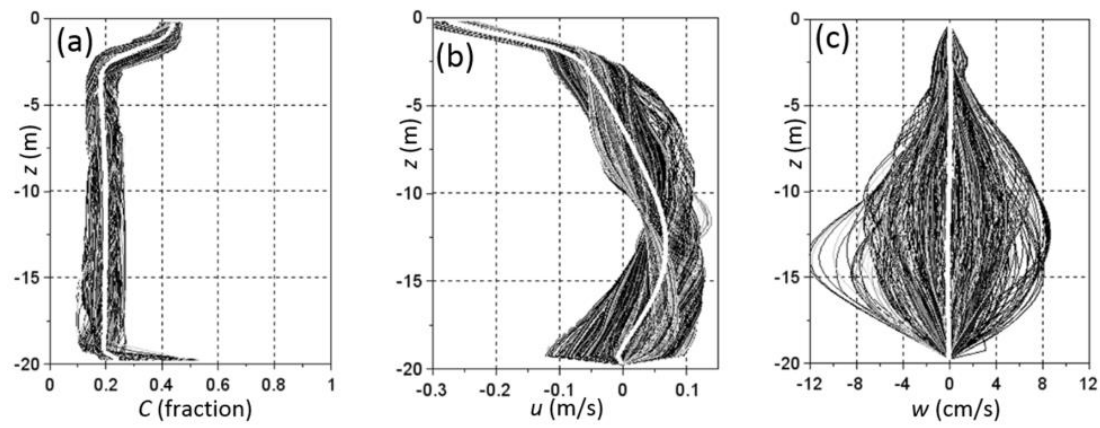

Figure 6. Scenario A $(N=0)$ with $\tau_{x}=-0.1 \mathrm{~Pa}$. The graphs display all vertical profiles within the interval of $x=[200 \mathrm{~m}, 400 \mathrm{~m}]$ after $6 \mathrm{~h}$ of simulation of (a) concentration field $C$; (b) horizontal velocity $u$; and (c) vertical velocity $w$. Thick white lines show horizontally averaged profiles.

Turbulent vortices emanate from the downwind shore of the model domain (Figure 6a). The Kelvin-Helmholtz instability mechanism [26] is the principal source of this instability. For homogeneous and stratified inviscid flows, a small number of criteria are necessary for this instability to develop [26]: (i) the Richardson number $\mathrm{Ri}=N^{2} /(d U / d z)^{\prime}$ less than $\frac{1}{4}$ at some level in the flow (known as the Miles-Howard criterion); (ii) if $N=0$ everywhere, $d^{2} u / d z^{2}$ changes sign at some level in the flow (known as Rayleigh's criterion); (iii) again, if $N=0, d^{2} U / d z^{2}\left[U-U\left(z_{i}\right)\right]<0$ at some level, where $z_{i}$ is the level of the inflection point in (ii) (known as the Fjortoft criterion). An overturning circulation with a level of no motion at a given level $z_{0}$ can be decomposed into a Fourier series with terms of $U=u_{0} \sin \left(z-z_{0}\right)$. Such velocity profiles, where $z_{0}$ is the inflection point, satisfy both (ii) and (iii). In fact, it is proved in [27] that any velocity profile being antisymmetric about $z_{0}$, that is, $U\left(-z^{*}\right)=-U\left(z^{*}\right)$ with $z^{*}=z-z_{0}$, can develop instabilities. Here, the instability mechanism is initiated near the downwind shore where the undercurrent develops first. Indeed, the simulated shear-flow instabilities can be eliminated from the simulation when using a coarser numerical grid and/or enlarged values of eddy viscosities.

There is a significant difference in the dynamical behaviour between the downwind and upwind shores of the model domain. Why? The explanation is that water upwelling near the upwind boundary enters the surface with zero horizontal momentum before it becomes exposed to acceleration by the wind. In contrast, water reaching the downwind boundary has already build up horizontal momentum on transit and it thus approaches the shore with a relatively high speed (Figure 7). Hence, the horizontal flow convergence inducing downwelling near the downwind boundary is several orders of magnitude larger than the flow divergence triggering upwelling near the upwind boundary. Due to 
volume conservation the undercurrent also attains the highest speed near the downwind boundary. Accordingly and further enhanced by shallow water effects, the velocity shear associated with the overturning circulation is strongest in vicinity of the downwind shore and that is the principal reason why dynamic instabilities are formed there first.

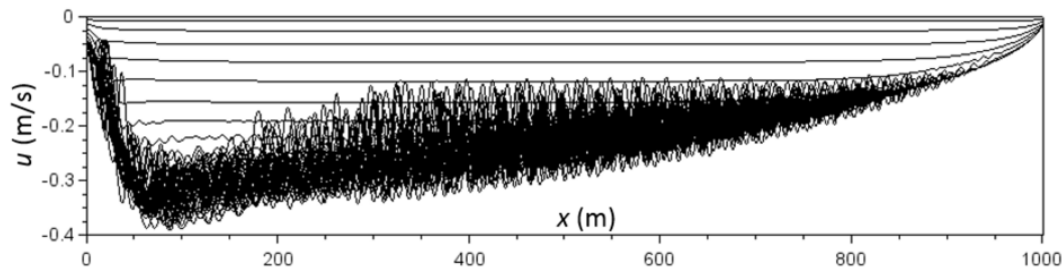

Figure 7. Scenario A $(N=0)$ with $\tau_{x}=-0.1 \mathrm{~Pa}$. Evolution of horizontal velocity $u(\mathrm{~m} / \mathrm{s})$ at the surface shown every $10 \mathrm{~min}$ of the simulation.

\subsection{Scenario B: Linear Density Stratification}

In the presence of linear density stratification, the surface flow creates downwelling near the downwind shore which pushes down isopycnals (Figure 8a). The overturning circulation develops within the uppermost 7-10 $\mathrm{m}$ of the water column. Shear flow instability near the downwind boundary creates internal gravity waves propagating against the wind direction (Figure 8a-c). Vigorous vertical mixing now becomes apparent in the density field via the breaking of internal waves. In contrast to the homogenous case (Scenario A), the overturning circulation does not penetrate into deeper layers of the water column. Instead, vertical mixing creates and is limited to a surface mixed layer of $\sim 10 \mathrm{~m}$ in thickness (Figure 9a). Note that the upwelling near the upwind shore is also confined to the depth of the surface mixed layer.
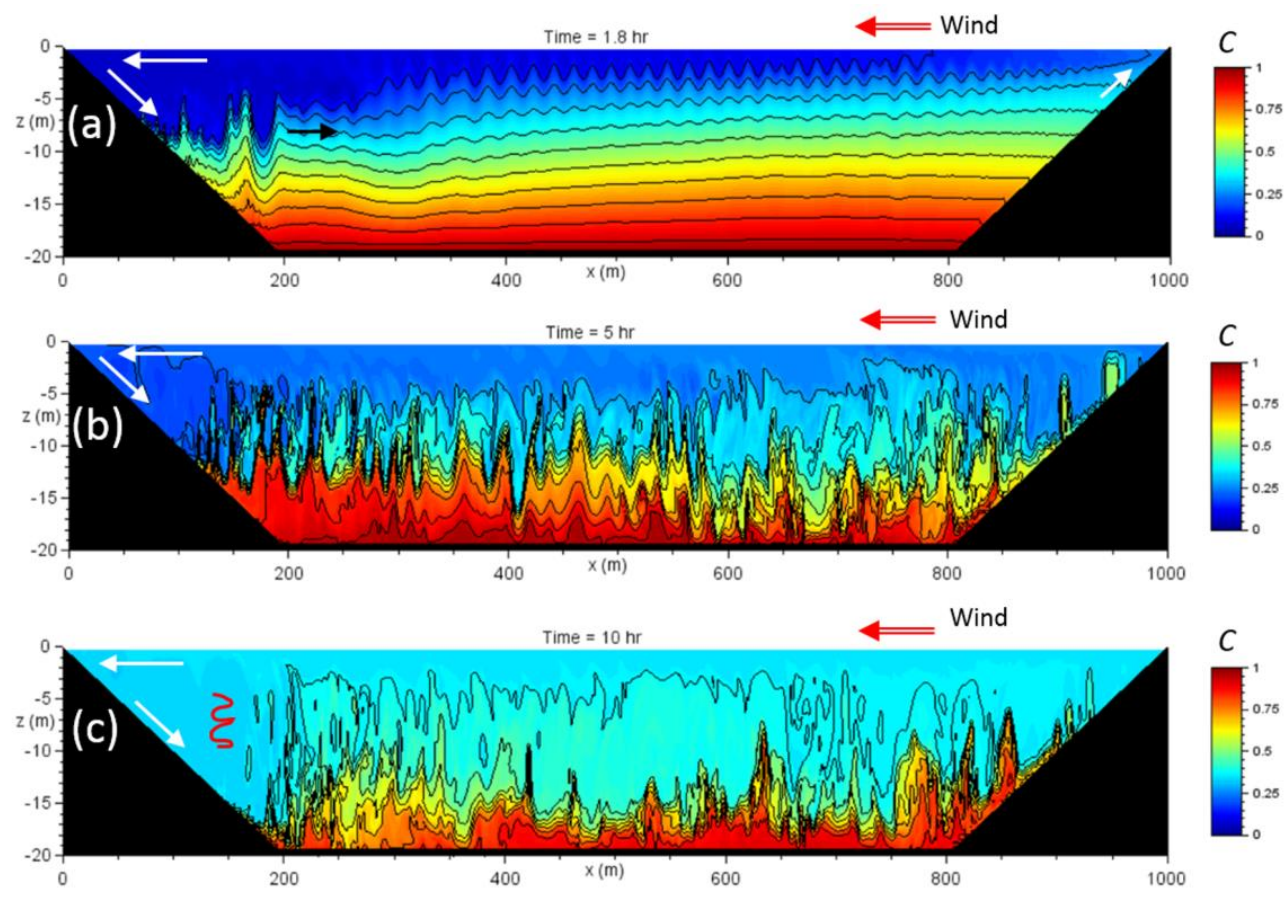

Figure 8. Same as Figure 4, but for Scenario B with $\tau_{x}=-0.1 \mathrm{~Pa}$ and $N^{2}=2 \times 10^{-4} \mathrm{~s}^{-2}$. Shown is the evolution of the concentration field $C$ after (a) $1.8 \mathrm{~h},(\mathbf{b}) 5 \mathrm{~h}$ and (c) $10 \mathrm{~h}$ of simulation. See GIF Animation S2 for a simulation of this experiment. 

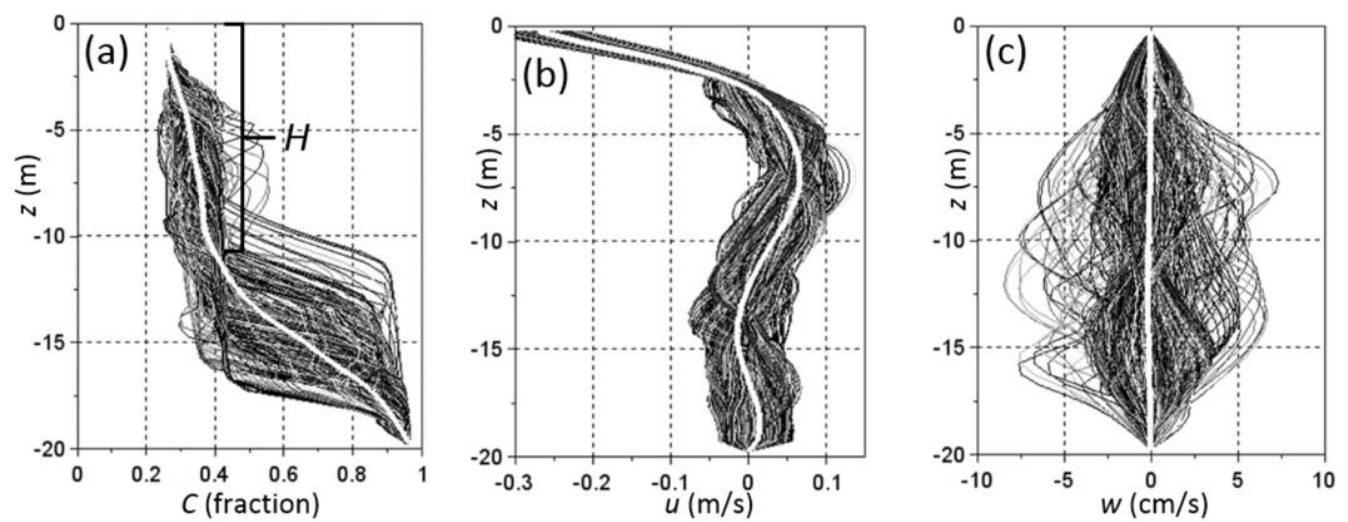

Figure 9. Same as Figure 6, but for Scenario B with $\tau_{x}=-0.1 \mathrm{~Pa}$ and $N^{2}=2 \times 10^{-4} \mathrm{~s}^{-2}$. The graphs display all vertical profiles within the interval of $x=[200 \mathrm{~m}, 400 \mathrm{~m}]$ after $6 \mathrm{~h}$ of simulation of (a) concentration field $C$; (b) horizontal velocity $u$; and (c) vertical velocity $w$. Thick white lines show horizontally averaged profiles. The symbol $H$ denotes the surface mixed layer that has formed in this experiment.

Another difference to the homogeneous density case is that the undercurrent is displaced upward in the water column (Figure 9b, compare with Figure 6b), and it is now vertically constrained by the newly formed pycnocline. Alternating bands of weak downwind and upwind flows develop below the pycnocline. Similar alternating zonal flow pattern are found in the equator ocean, but on much larger spatial scales [28]. After establishment of the surface mixed layer, vertical velocities tend to peak with speeds of around $2-3 \mathrm{~cm} / \mathrm{s}$ at $\sim 12-13 \mathrm{~m}$ depth (Figure $9 \mathrm{c}$ ), which is near the base of the mixed layer (see Figure 8c).

The shear-flow instabilities that emanate from the downwind shore are responsible for the creation of a surface mixed layer. The thickness of this layer depends on the degree of density stratification and the intensity of the wind forcing. A sequence of model experiments indicates that this thickness, $H$, is proportional to the length scale $u^{*} / N$ (Figure 10a), where $u^{*}$ is the wind-friction velocity. This relation implies that enhanced density stratification reduces the intensity and vertical reach of dynamic instabilities that form near the downwind boundary. Hence, the proposed dynamic instability mechanism is more effective if it occurs in conjunction with other preconditioning processes (e.g., tidal mixing or wind-driven Ekman downwelling) that operate to reduce the static stability in nearshore water.

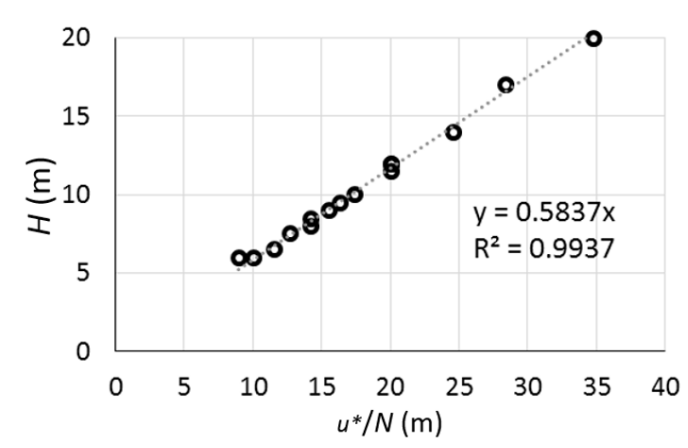

Figure 10. Scenario B. Initial thickness, $H$, of the surface mixed layer plotted against the length scale $u^{*} / N$, where $u^{*}=\left(\tau_{x} / \rho_{0}\right)^{1 / 2}$ is the wind-friction velocity. Shown are the results of 15 different model configurations for wind-stress magnitudes between 0.05 and $0.15 \mathrm{~Pa}$ and values of $N^{2}$ ranging between $1 \times 10^{-4} \mathrm{~s}^{-2}$ and $5 \times 10^{-4} \mathrm{~s}^{-2}$. 
The internal waves created here share characteristics of waves inherent with the "oceanic wave guide"; that is, internal waves in a layer of fluid with constant $N$ and vanishing vertical velocities at both vertical boundaries $[29,30]$. Some of the waves predicted here are inherent with the creation of the surface mixed layer, while others are propagating offshore. Nevertheless, the shear-flow instability process, which creates both breaking and nonbreaking internal waves in the stratified fluid, continues to exist in the homogenous case where internal waves cease to exist. To this end, it is surprising to note the high similarity of fluctuations in vertical velocity characterizing either case (see Figure $9 \mathrm{c}$, compare with Figure 6c).

\subsection{Scenario C: Layered Density Configuration}

With the existence of a shallow pycnocline, the shear-flow instability mechanism creates internal waves at the base of the pycnocline throughout the entire domain (Figure 11a). The downwelling process near the downwind boundary still generates its own internal waves, which becomes apparent as these reflect from the upwind boundary (Figure 11b). Here, reflection doubles the wave amplitude and triggers mixed-layer deepening to a depth of $>6 \mathrm{~m}$. Under the action of breaking internal waves, sub-surface water from depths of up to $10 \mathrm{~m}$ becomes entrained into the surface mixed layer (Figure 12). Wave reflection and breaking on sloping boundaries, similar to the results shown here, have been extensively studied before (e.g., [20-24]). On timescales of $10 \mathrm{~h}$, such reflection patterns can only develop in closed water bodies on horizontal scales of less than a few kilometres.

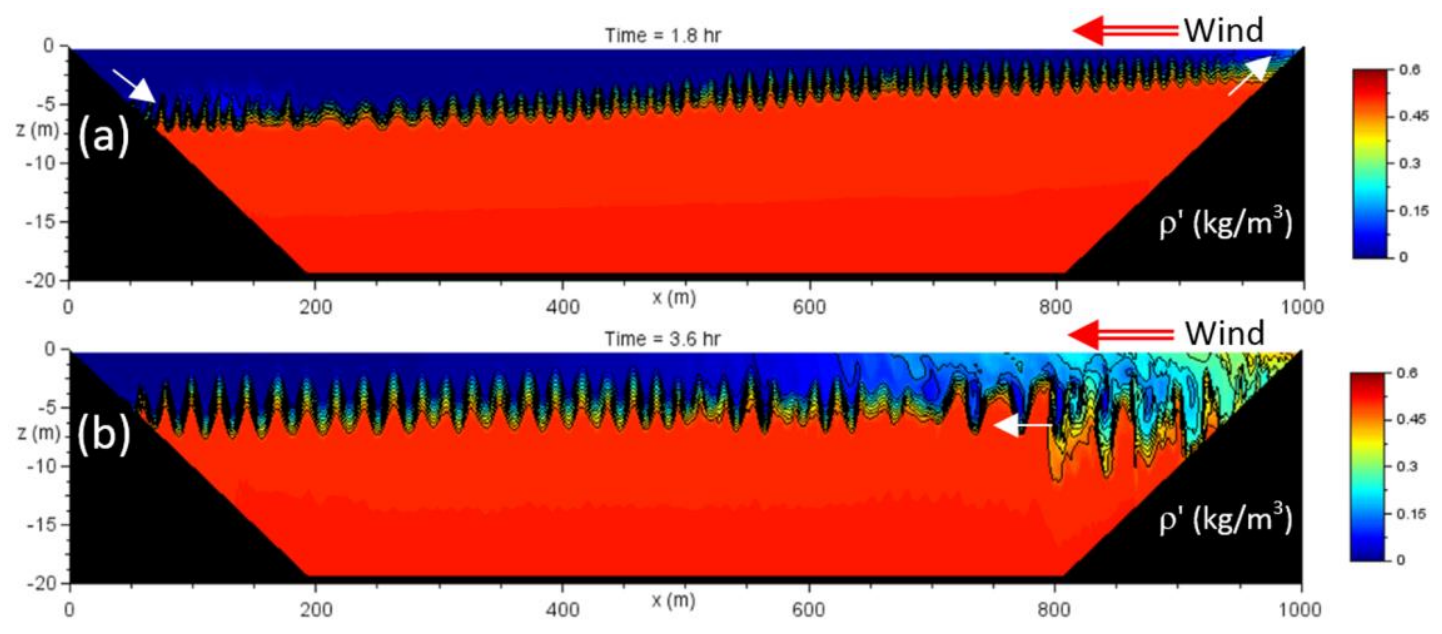

Figure 11. Scenario $\mathrm{C}$ with $\tau_{x}=-0.1 \mathrm{~Pa}$ and $\Delta \rho=0.5 \mathrm{~kg} / \mathrm{m}^{3}$. Shown are density distributions after (a) $1.8 \mathrm{~h}$ and (b) $3.6 \mathrm{~h}$ of simulation. The small arrow in panel (b) indicates the propagation direction of internal waves after reflection. See GIF Animation S3 for a simulation of this experiment. by [17]:

The phase speed of internal waves in a two-layer fluid of layer thicknesses of $D_{1}$ and $D_{2}$ is given

$$
c=\sqrt{g^{\prime} D_{1} D_{2} / D}
$$

Here $\left(D_{1}=5 \mathrm{~m}, D_{2}=15 \mathrm{~m}, D=20 \mathrm{~m}, \Delta \rho=0.5 \mathrm{~kg} / \mathrm{m}^{3}, g^{\prime} \approx 4.8 \times 10^{-4} \mathrm{~m} / \mathrm{s}^{2}\right)$, relation (10) yields a phase speed of $\sim 13 \mathrm{~cm} / \mathrm{s}$ so that, after their creation, it takes internal waves $\sim 2 \mathrm{~h}$ to cross the domain.

A weaker pycnocline $\left(\Delta \rho=0.1 \mathrm{~kg} / \mathrm{m}^{3}, g^{\prime} \approx 9.6 \times 10^{-5} \mathrm{~m} / \mathrm{s}^{2}\right)$ again triggers the creation of interfacial waves emanating from the downwind shore (Figure 13a). The waves attain a reduced phase speed of $6 \mathrm{~cm} / \mathrm{s}$, which takes them a time of $4.6 \mathrm{~h}$ to travel a distance of $1 \mathrm{~km}$. Again, wave reflection induces vigorous mixing near the upwind shore, while the Kelvin-Helmholtz instability mechanism leads to enhanced vertical stirring near the downwind shore (Figure 13b). Over time and supported by wave reflection at both boundaries, the entire water body becomes well mixed (Figure 13c). 


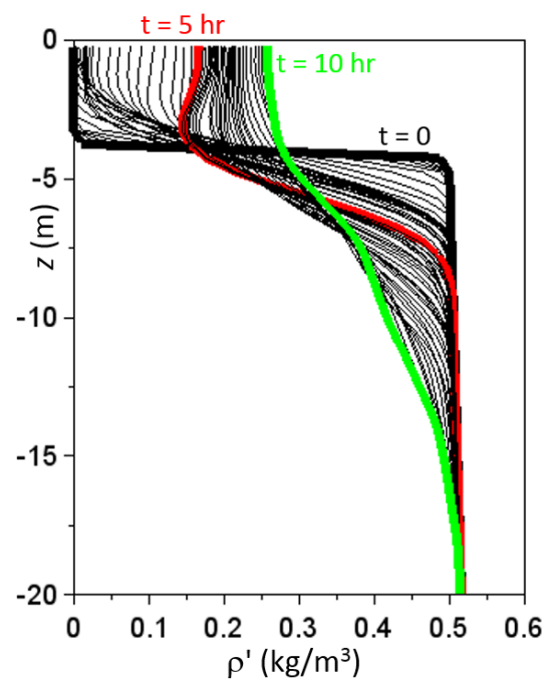

Figure 12. Scenario $\mathrm{C}$ with $\tau_{x}=-0.1 \mathrm{~Pa}$ and $\Delta \rho=0.5 \mathrm{~kg} / \mathrm{m}^{3}$. Evolution of horizontally averaged density profiles within the region of $x=[200 \mathrm{~m}, 800 \mathrm{~m}]$. Profiles after $5 \mathrm{~h}$ and $10 \mathrm{~h}$ are highlighted.
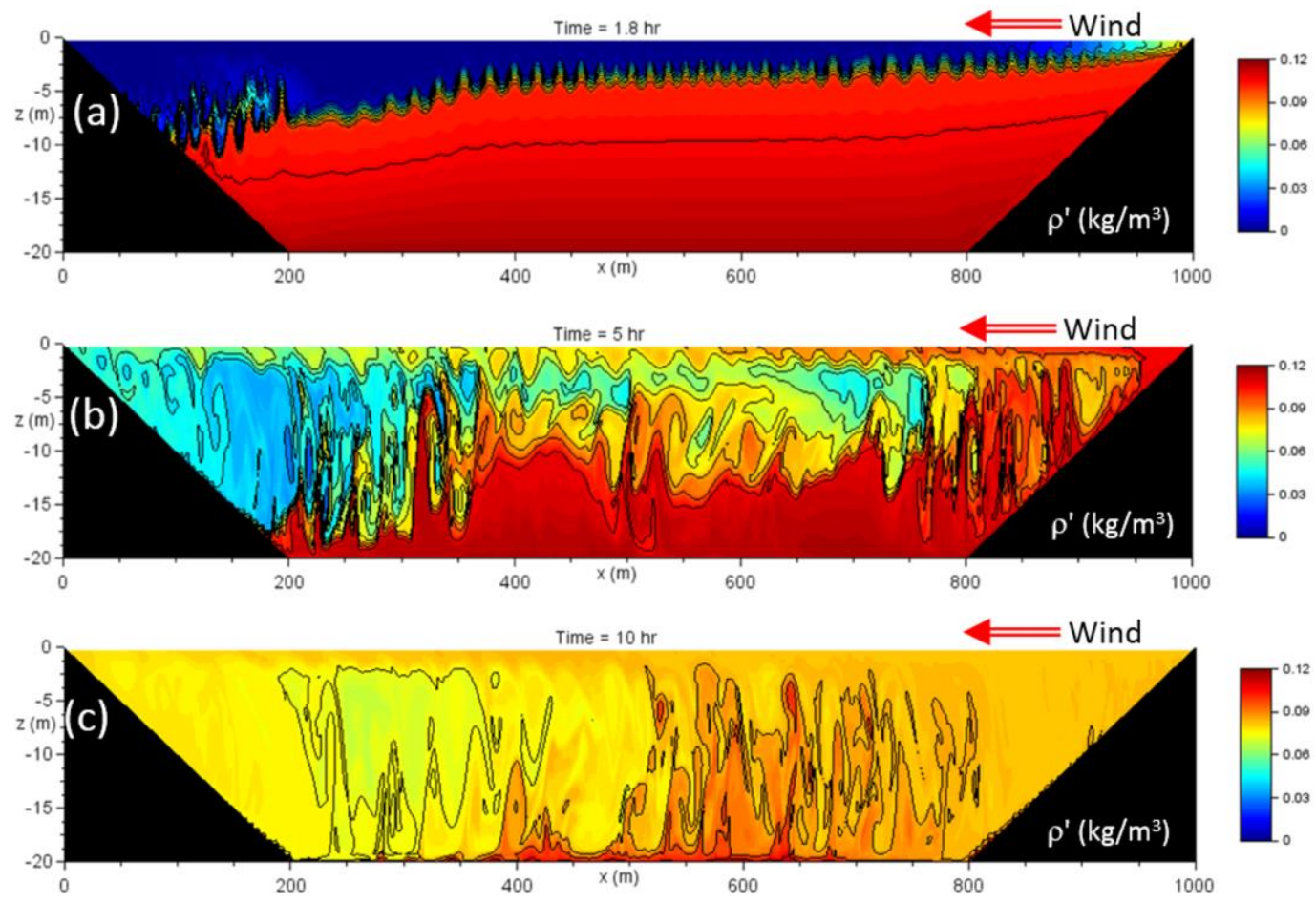

Figure 13. Scenario $\mathrm{C}$ with $\tau_{x}=-0.1 \mathrm{~Pa}$ and $\Delta \rho=0.1 \mathrm{~kg} / \mathrm{m}^{3}$. Shown are density distributions after (a) $1.8 \mathrm{~h}$; (b) $5 \mathrm{~h}$; and (c) $10 \mathrm{~h}$ of simulation. Small arrows indicate the propagation direction of internal waves. See GIF Animation S4 for a simulation of this experiment.

Inspection of the evolution of the vertical density structure (Figure 14) reveals another interesting aspect associated with the simulated overturning circulation. During the first $5 \mathrm{~h}$ of simulation, a pronounced density-unstable boundary layer establishes in the uppermost 2-3 $\mathrm{m}$ of the water column, which supports convective instabilities [17]. This mechanism, created via upwelling at the upwind boundary and offshore advection of denser surface water, may also contribute to the simulated vertical stirring. 


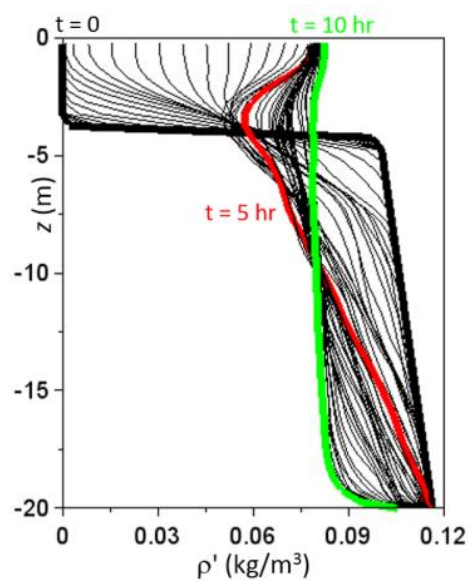

Figure 14. Same as Figure 12, but for Scenario $C$ with $\tau_{x}=-0.1 \mathrm{~Pa}$ and $\Delta \rho=0.1 \mathrm{~kg} / \mathrm{m}^{3}$.

\section{Discussion}

The results of process-oriented numerical modelling, presented above, demonstrate that onshore winds are a principal agent of internal wave generation and vigorous vertical mixing in shallow lakes, near the shores of deep lakes, and on the inner continental shelves of the oceans. This mechanism is presumably highly relevant to biogeochemical cycles in shallow water as it supports upward nutrient fluxes and, potentially, also the recycling of nutrients from the bed. As the proposed mechanism creates large-amplitude internal waves propagating offshore after each onshore wind pulse, it also contributes to the dissipation of energy in the oceans [31]. Indeed, there are ample studies on the generation and modification of waves over variable topography in shelf seas and lakes (e.g., [19-25]), but as far as the author is aware, the fundamental mechanism of wave generation due to instabilities of the overturning circulation that forms under onshore winds has not been described before.

Previous modelling studies by [18] explored the wind-induced near-shore circulation on subinertial timescales of up to 10 days, which per se includes rotational effects due to the Coriolis force. The model used a Mellor-Yamada level-2.5 turbulence closure scheme, which induced enhanced vertical mixing in shallow nearshore water, in agreement with the direct simulations presented here. Nevertheless, despite the thematic similarity, the findings by [18] are fundamentally different as the model used did not resolve nonhydrostatic processes. To this end, [18] could not capture the creation of internal waves, which appear as a fundamental side effect of the wind-induced overturning process. The present work also demonstrates that most of the instabilities and internal waves are created within a few hours and, hence, long before rotational effects become influential, as confirmed by additional simulations (Figure 15). Moreover, [18] proposed a formula for the surface boundary layer depth similar to and based on the classical scaling depth of the Ekman layer, $u^{*} / f$ [32]. This depth, however, establishes relatively slowly on a rotational timescale of several days and not in due course of a few hours of wind forcing as studied here. Hence, the scaling depth of the surface mixed layer, $u^{*} / N$, proposed here, is different to that developing on longer timescales. 

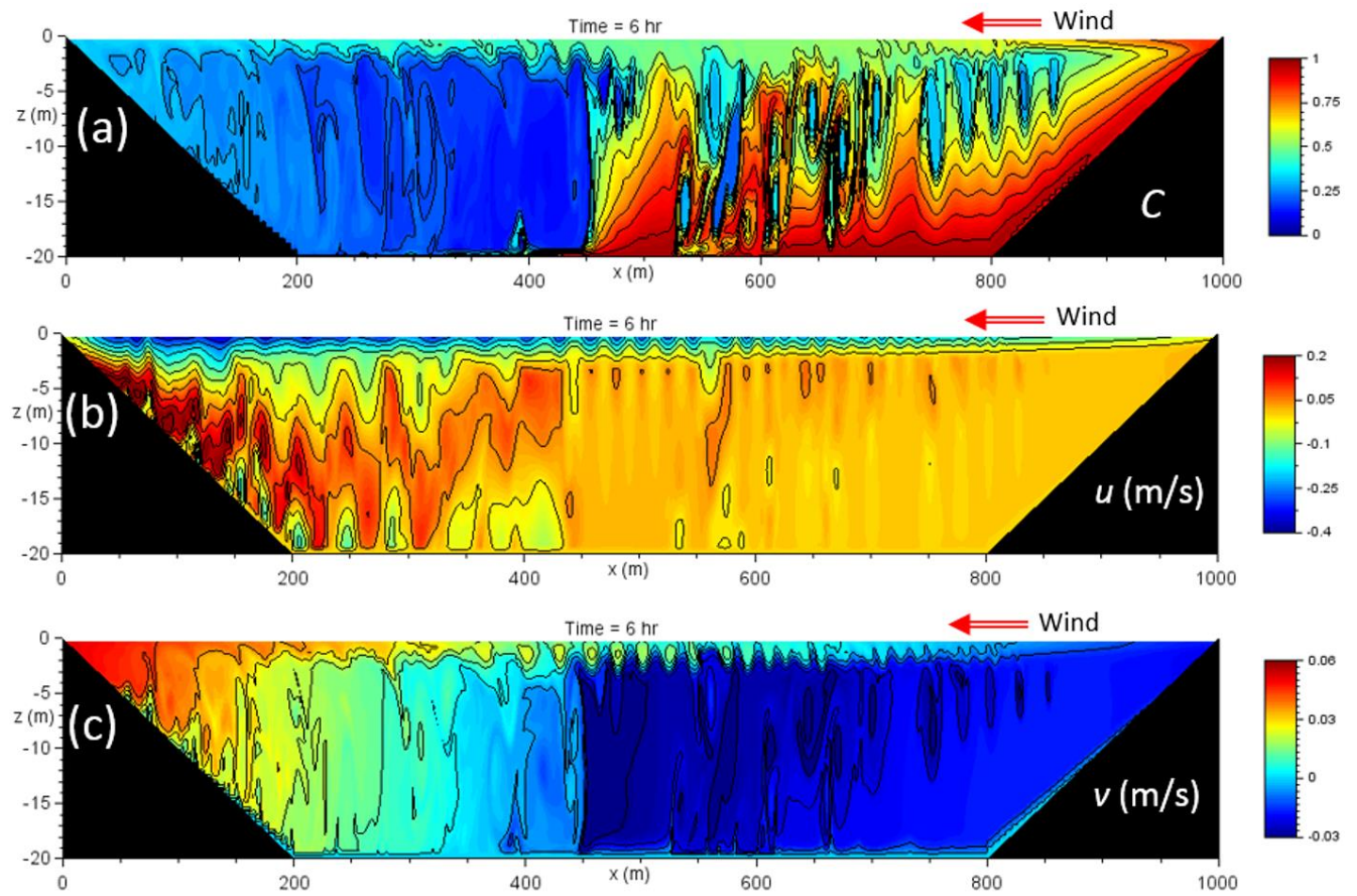

Figure 15. Scenario $\mathrm{A}(N=0)$ with $\tau_{x}=-0.1 \mathrm{~Pa}$, simulated with the 2.5-dimensional version of the nonhydrostatic model (see [17]) accounting for rotational effects using a Coriolis parameter of $f=1 \times 10^{-4} \mathrm{~s}^{-1}$. Shown are the distributions after $6 \mathrm{~h}$ of simulation of (a) the concentration field $C$ (compare with Figure 4b); (b) offshore velocity $u$ (compare with Figure 5a) and (c) alongshore velocity $v$. Except for the creation of a weak alongshore flow near the downwind boundary, rotational effects have little influence on the dynamics on this timescale.

Findings of this work indicate that the proposed instability mechanism, which follows from the overturning circulation created near downwind boundaries, is most efficient under weak density stratification. Hence, other processes reducing density stratification in near-shore water operate to precondition the water column for vigorous vertical stirring under onshore winds events. These preconditioning processes include classical wind-driven Ekman upwelling or downwelling episodes (following from alongshore winds), density-driven convection or tidal mixing.

While the model domain chosen resembles a closed lake, on timescales of a few hours considered in this study, the dynamic processes evolving near the downwind and upwind coasts are identical to those expected to occur in coastal oceans, as confirmed by additional studies (not shown) using wider model domains or an open offshore boundary.

Indeed, this model application was highly simplified and calls for more realistic numerical studies that include the effects of surface gravity waves, three-dimensionality, and the Coriolis force. It is well documented that wave-induced Stokes drift creates localized rip currents [33] that form and interact with seabed undulations. Interesting questions for future research are to address whether wind-driven undercurrents are localized features and how they interact with rip currents and seafloor morphology.

The author hopes that this work motivates others to inspect past data sets and to undertake new field surveys or laboratory experiments in search of turbulence and internal waves created by onshore winds.

Supplementary Materials: The following are available online at http://www.mdpi.com/2077-1312/5/4/ 47/s1, GIF Animation S1: animScenarioA.gif, GIF Animation S2: animScenarioB.gif, GIF Animation S3: animScenarioC1.gif, GIF Animation S4: animScenarioC2.gif. 
Acknowledgments: This work has not received external funding. The author is grateful for the comments and criticism by three anonymous referees.

Conflicts of Interest: The author declares no conflict of interest.

\section{References}

1. Kämpf, J.; Chapman, P. Upwelling Systems of the World: A Scientific Journal to the Most Productive Marine Ecosystems; Springer International Publishing: Cham, Switzerland, 2016; pp. 31-65.

2. Ekman, V.W. On the influence of the Earth's rotation on ocean currents. Ark. Mat. Astron. Fys. 1905, 2, 1-52.

3. Hutter, K. Hydrodynamics of Lakes; Springer: Berlin, Germany, 1983.

4. Wüest, A.; Lorke, A. Small-scale hydrodynamics in lakes. Annu. Rev. Fluid Mech. 2003, 35, 373-412. [CrossRef]

5. Kämpf, J. Interference of wind-driven and pressure gradient-driven flows in shallow homogeneous water bodies. Ocean Dyn. 2015, 65, 1399-1410. [CrossRef]

6. Lentz, S.J.; Fewings, M.R. The wind-and wave-driven inner-shelf circulation. Ann. Rev. Mar. Sci. 2012, 4, 317-343. [CrossRef] [PubMed]

7. Hela, I. Vertical velocity of the upwelling in the sea. Soc. Sci. Fenn. Comment. Phys. Math. 1976, 46, 9-24.

8. Monismith, S.G. Wind-forced motions in stratified lakes and their effect on mixed-layer shear. Limnol. Oceanogr. 1985, 30, 771-783. [CrossRef]

9. Monismith, S.G. An experimental study of the upwelling response of stratified reservoirs to surface shear stress. J. Fluid Mech. 1986, 171, 407-439. [CrossRef]

10. Stevens, C.; Imberger, J. The initial response of a stratified lake to a surface shear stress. J. Fluid Mech. 1996, 312, 39-66. [CrossRef]

11. Farrow, D.E.; Stevens, C.L. Numerical modelling of a surface-stress driven density stratified fluid. J. Eng. Math. 2003, 47, 1-16. [CrossRef]

12. Svannsson, A. Interaction between the coastal zone and the open sea. Finn. Mar. Res. 1975, 239, 11-28.

13. Myrberg, K.; Andrejev, O. Main upwelling regions in the Baltic Sea-A statistical analysis based on three-dimensional modeling. Boreal Environ. Res. 2003, 8, 97-112.

14. Kämpf, J. Undercurrent-driven upwelling in the northwestern Arafura Sea. Geophys. Res. Lett. 2015, 42, 9362-9368. [CrossRef]

15. Kämpf, J. On the majestic seasonal upwelling system of the Arafura Sea. J. Geophys. Res. Oceans 2016, 121, 1218-1228. [CrossRef]

16. Kämpf, J. Ocean Modelling for Beginners; Springer: Heidelberg, Germany, 2009; pp. 1-170.

17. Kämpf, J. Advanced Ocean Modelling; Springer: Heidelberg, Germany, 2010; pp. 1-181.

18. Tilburg, C.E. Across-shelf transport on a continental shelf: Do across-shelf winds matter? J. Phys. Oceanogr. 2003, 33, 2675-2688. [CrossRef]

19. Afanasyev, Y.D.; Peltier, W.R. On breaking internal waves over the sill in Knight Inlet. Proc. R. Soc. Lond. A 2001, 457, 2799-2825. [CrossRef]

20. Horn, D.A.; Imberger, J.; Ivey, G.N. The degeneration of large-scale interfacial gravity waves in lakes. J. Fluid Mech. 2001, 434, 181-207. [CrossRef]

21. Boegman, L.; Ivey, G.N.; Imberger, J. The degeneration of internal waves in lakes with sloping topography. Limnol. Oceanogr. 2005, 50, 1620-1637. [CrossRef]

22. Ivey, G.N.; Nokes, R.I. Vertical mixing due to the breaking of critical internal waves on sloping boundaries. J. Fluid Mech. 1989, 204, 479-500. [CrossRef]

23. Legg, S.; Adcroft, A. Internal wave breaking at concave and convex continental slopes. J. Phys. Oceanogr. 2003, 33, 2224-2246. [CrossRef]

24. Helfrich, K.R. Internal solitary wave breaking and run-up on a uniform slope. J. Fluid Mech. 1992, 243, 133-154. [CrossRef]

25. Kochergin, V.P. Three-dimensional prognostic models. In Three-Dimensional Coastal Ocean Models; Hepas, N.S., Ed.; Coastal and Estuarine Science 4; American Geophysical Union: Washington, DC, USA, 1987; pp. 201-208.

26. Drazin, P.G.; Reid, W.H. Hydrodynamic Stability; Cambridge University Press: Cambridge, UK, 1981; 525p.

27. Baines, P.G.; Mitsudera, H. On the mechanism of shear flow instabilities. J. Fluid Mech. 1994, 276, 327-342. [CrossRef] 
28. Tomczak, M.; Godfrey, J.S. Regional Oceanography: An Introduction, 2nd ed.; Daya Publishing House: Delhi, India, 2003; p. 185.

29. Gill, A.E. Atmosphere-Ocean Dynamics; Academic Press: London, UK, 1982; pp. 154-162.

30. Munk, W.H. Internal waves and small-scale processes. In Evolution of Physical Oceanography; Warren, B.A., Wunsch, C., Eds.; The MIT Press: Cambridge, MA, USA, 1981; Chapter 9; pp. 264-291.

31. Wunsch, C.; Ferrari, R. Vertical mixing, energy, and the general circulation of the oceans. Annu. Rev. Fluid Mech. 2004, 36, 281-314. [CrossRef]

32. Csanady, G.T. On the 'resistance law' of a turbulent Ekman layer. J. Atmos. Sci. 1967, 24, 467-471. [CrossRef]

33. Johnson, D.; Pattiaratchi, C. Boussinesq modelling of transient rip currents. Coast. Eng. 2006, 53, 419-439. [CrossRef]

(C) 2017 by the author. Licensee MDPI, Basel, Switzerland. This article is an open access article distributed under the terms and conditions of the Creative Commons Attribution (CC BY) license (http:/ / creativecommons.org/licenses/by/4.0/). 